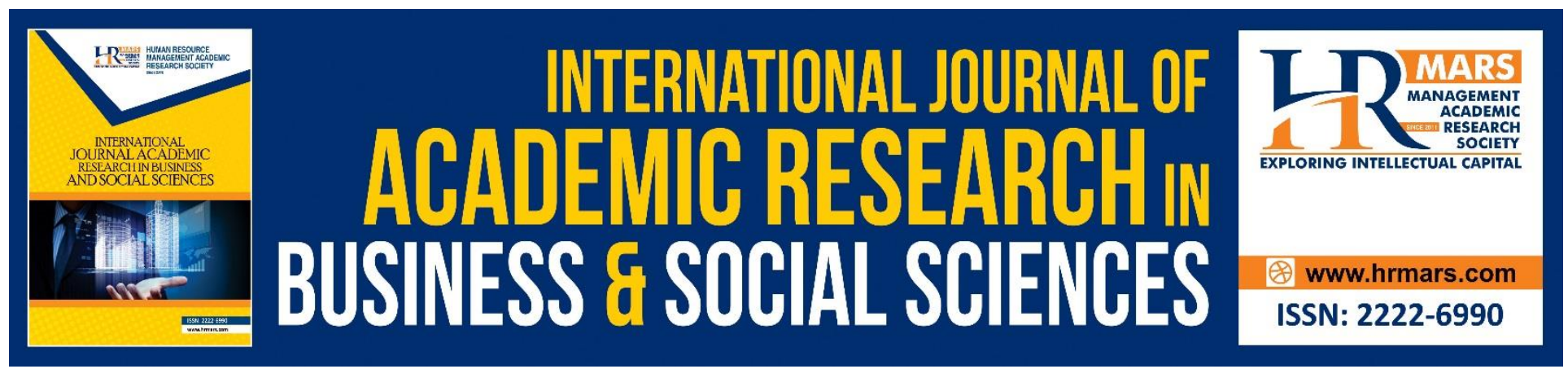

\title{
Predictor Factor on Relapse among Former Addicts
}

\section{Asbah Razali and Zainal Madon}

To Link this Article: http://dx.doi.org/10.6007/IJARBSS/v10-i16/8311

DOI:10.6007/IJARBSS/v10-i16/8311

Received: 16 October 2020, Revised: 12 November 2020, Accepted: 12 December 2020

Published Online: 21 December 2020

In-Text Citation: (Razali \& Madon, 2020)

To Cite this Article: Razali, A., \& Madon, Z. (2020). Predictor Factor on Relapse among Former Addicts. International Journal Academic Research in Business and Social Sciences, 10(16), 278-288.

\section{Copyright: (c) 2020 The Author(s)}

Published by Human Resource Management Academic Research Society (www.hrmars.com)

This article is published under the Creative Commons Attribution (CC BY 4.0) license. Anyone may reproduce, distribute, translate and create derivative works of this article (for both commercial and non-commercial purposes), subject to full attribution to the original publication and authors. The full terms of this license may be seen

at: http://creativecommons.org/licences/by/4.0/legalcode

Special Issue: Youth and Community Wellbeing: Issues, Challenges and Opportunities for Empowerment V2, 2020, Pg. 278 - 288 http://hrmars.com/index.php/pages/detail/IJARBSS JOURNAL HOMEPAGE

Full Terms \& Conditions of access and use can be found at http://hrmars.com/index.php/pages/detail/publication-ethics 


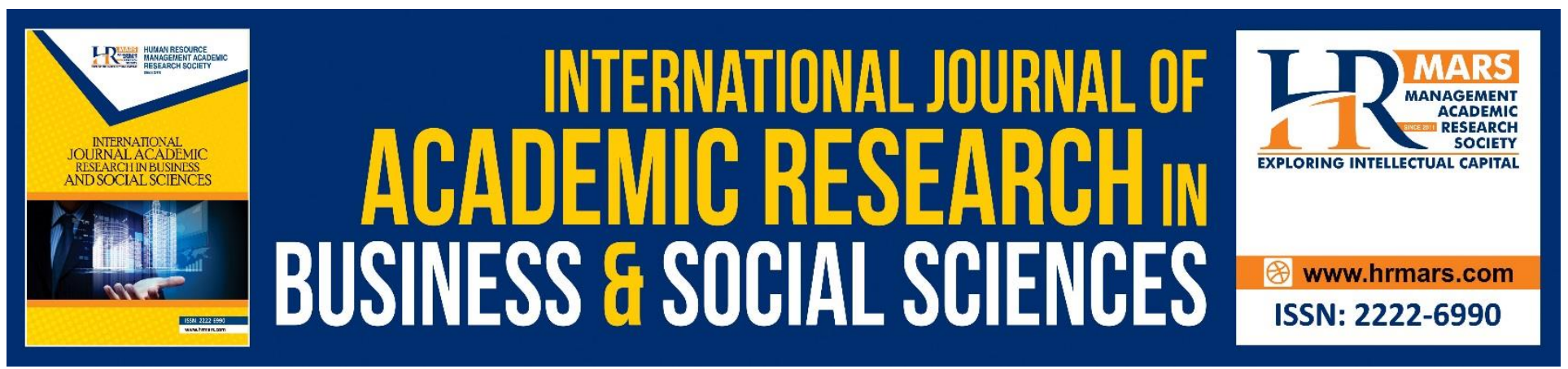

\title{
Predictor Factor on Relapse among Former Addicts
}

\author{
Asbah Razali ${ }^{2}$ and Zainal Madon ${ }^{1,3}$ \\ ${ }^{1}$ Institute of Social Science Study, Putra Infoport, Universiti Putra Malaysia, 43400, UPM Serdang, \\ Selangor, Malaysia, ${ }^{2}$ Department of Anthropology and Sociology, Faculty of Art and Social Sciences, \\ University of Malaya, Kuala Lumpur, Malaysia, ${ }^{3}$ Department of Human Development and Family \\ Studies, Faculty of Ecology, University Putra Malaysia, Selangor, Malaysia \\ Email: asbahrazali@um.edu.my,zainalm@upm.edu.my
}

\begin{abstract}
The inclination to relapse among drug addicts is related to the desire of former addicts to relapse drugs after the end of their treatment and rehabilitation process. Identifying the predictor factor for the inclination to relapse among former addicts could not only prevent relapse, but also recognise the largest influence in their lives that contribute to their relapse. This study uses the questionnaires of the Inventory of Drug-Taking Situations, General Self Efficacy, Coping Strategy and Social Provisions Scale. The findings show there are six identifiable significant predictor variables and the main contributors to the inclination to relapse; problem-focused coping, emotion-focused coping, avoidance coping, self-efficacy, family support, and peer support towards the inclination to relapse. Based on the results, it could be concluded that these six predictor variables have been identified as significant and the main contributors to the inclination to relapse. The findings also found self-efficacy to have a significant effect on the inclination to relapse. This study could indirectly aid the government in their efforts to overcome the drug problem, and benefit the affected parties in formulating various rehabilitation and prevention programmes for former addicts, as failure to solve this problem not only threatens the lives of individuals, but also the national social and economic development.
\end{abstract}

\section{Introduction}

The inclination to relapse is one of the psychological and behavioural problems. According to a report published by the Substance Abuse and Mental Health Services Administration (SAMHSA) in 2014, more than 50 per cent of drug addicts are inclined to relapse after the end of their treatment and rehabilitation process. They are close to high-risk situations to relapse due to negative responses and inability to counter these responses. Although some former addicts have the self-restraint to relapse drugs, other are unable to overcome their desire to re-use. Multiple factors have been identified to influence drug addicts to relapse drugs and fulfil one's needs. Therefore, they require strength to fight the desire for drugs (Bowen, Witkiewitz, Clifasefi, Grow, Chawla \& Hsu, 2014). Studies on this 
issue have been carried out by many scholars in the West (such as Bowen, Chawla \& Marlatt, 2010, Greenfield, Brooks, Gordon, Green, Krop \& McHugh, 2007; White, Campbell, Spencer, Hoffman, Crissman \& DuPont, 2014; Tate, Brown, Glasner, Unrod \& McQuaid, 2006), but similar studies in Malaysia on the inclination to relapse is still inconsistent. Studies in the West mostly found the inclination to relapse to be caused by certain factors, such as self-pressure, emotional stress, social environmental stress, such as family support, peer support, and societal support. In addition, the inclination to relapse scenario among addicts in Malaysia is also significant based on social environmental factors, personal stress, emotional stress, and interpersonal conflict, leading to the increase in the number of repeating addicts every year (Fauziah \& Naresh Kumar, 2009; Mahmud Mazlan, Schottenfeld \& Chawarski, 2006; Xu, 2014). Previous studies prove the inclination to relapse is not only caused by cognitive factors, but also by social environment such as family support, peer support, and societal support. These factors are closely linked and interplayed in the environmental system. This indirectly shows the importance in the role of the individual and the people around them, such as parents, peers, and members of society, in ensuring former drug addicts are successful in overcoming their desire for drugs.

Marlatt and Gordon (1985) explain there are two general definitions of relapse: (i) a disease symptom that returns after treatment and (ii) an action that indicates that patients either recover or become worse and incurable. Meanwhile, Gorski and Gossop, Green and Phillips (1989) define relapse as drug relapse after a stage of abstinence from drug use. However, the term 'relapse' from the quantity of drug re-use, either occasionally or continuously, is still debated among most scholars. Therefore, they require detailed planning to ensure their preparedness in facing any pressure and overcome difficulties, especially when they are financially lacking. Former addicts require a coping strategy to manage situations beyond their adjustment point. Coping basically is an action-oriented and intrapsychic effort to overcome, endure, reduce, or minimise both internal and environmental pressures and conflicts.

Furthermore, coping also refers to behaviour to control and overcome threats and challenges due to stress. It brings out positive effects for the individual, such as reducing and improving self-satisfaction. This viewpoint is in line with the research by Cornelius, Maisto and Pollock (2003), who studied 59 adolescents with drug problems and have completed their treatment and rehabilitation. This study found that around $66 \%$ of respondents have relapsed within six months after treatment and rehabilitation, and the average for drug use relapse is on the $54^{\text {th }}$ day, or almost two months after the end of treatment and rehabilitation. The results show this happens because addicts are unable to control themselves, leading to aggressiveness, acting out of control of expectation. Therefore, they require the avoidance coping strategy to guard against internal stress.

In addition, following the rehabilitation process for addicts is too complex, as they are often depicted as suffering from chronic disturbances, and potentially susceptible to relapse after treatment. Former addicts require social support to escape drug use. Among these support structures include family, peers, and society. These social supports can help drug addicts to experience positive changes in healing and forming trust with themselves. Sharma, Upadhyaya, Bansal, Nijhawan, and Sharma (2012), in their study focuses on 226 adolescent drug addicts between the ages of 13 and 20 years. This study 
INTERNATIONAL JOURNAL OF ACADEMIC RESEARCH IN BUSINESS AND SOCIAL SCIENCES

Vol. 10, No. 16, Youth and Community Wellbeing: Issues, Challenges and Opportunities for Empowerment V2. 2020, E-ISSN: 2222-6990 @) 2020 HRMARS

uses the Causes of Drug Misuse Scale (CADAS) and the Cures for Drug Misuse Scale. The findings show a link between family support and the inclination to relapse, with $r=.315, p<.01$. The findings also found a lack of family support causes stress among addicts, and a risk factor to relapse. Drug addicts with constant family support can persevere from relapse compared to addicts without family support.

Friends and peers are also main values and norms references in a young adult's development (Gouws, Kruger \& Burger, 2000). This is supported in previous studies by McWhirter, Rasheed, \& Crothers (2004) in their study on 250 former drug addicts, using the Peer Crowd Questionnaire (PCQ) inventory. Their findings show friends and peers are significant sources determining the main factor towards the inclination to relapse, affecting full recovery. Peer pressure to partake in socially negative activities leads youths to carry out wrongdoings. Former addicts, susceptible to friends with similar issues, would them form their own clique and partake in the same activities to feel a sense of belonging in that group (Georgie, Sean, Deborah, Matthew \& Rona, 2016).

Westreich, Heitner and Cooper (1997) in their research using the Functional Social Support Questionnaire (FSSQ) inventory looks as societal support among former drug addicts, and their findings also found societal support is negative to the inclination to relapse. 66 addicts were evaluated relating to social support after the end of treatment and rehabilitation. This study was carried out for 21 days after the end of treatment, in relation to societal support. Around 46 drug addicts participated in this study, while the remaining 20 were not included as they were unable to commit to the end of this research. The findings show social support plays a role in treating former addicts facing social pressure, and social perception is a key factor preventing them from relapsing to drug-use. These discussed previous studies prove social support is related to the inclination to relapse among former drug addicts.

Another study conducted by Samir, Maginsh and Ganga (2015) found that addictio drugs are a relapse chronic behaviour problem that can change mood, perception and the sensation of a former drug addict. The study was conducted to look at the factors related to relapse in Nepal on 114 respondents. The results of the study almost all users 94.9 percent of respondents no longer take drugs after treatment. The support gained by friend and family causes them to relapse. This means social support, covering societal support is necessary to ensure successful treatment and preventing the inclination to relapse. It is important to explore the main factor influencing the inclination to relapse. Therefore, this paper aims to identify the main predictor factors to the inclination to relapse among former drug addicts, and whether there are direct and indirect effects of the self-efficacy factor on the inclination to relapse among former drug addicts.

\section{Research Methodology}

The basic quantitative research design is used for this study. This study involved 242 former drug addicts that completed their treatment and rehabilitation period. All respondents were selected in this study is male respondents aged between 16 to 35 years using the Inventory of Drug-Taking Situations, by Annis and Martin (1985), General Self Efficacy by Sherer and Maddux (1982), Coping Strategy by Carver, Scheier and Weintraub (1989), and Social Provisions Scale (SPS) by Russell and Cutrona (1987). For this study, data collection was using cluster sampling technique. Cluster sampling 
is a sampling technique where all the units in the group will be selected. Four Cure and Care Rehabilitation Centre (CCRC) were selected by zones; The North, South, Central, and East zones, representing the population in this study based on cluster sampling. The questionnaires used for this study The measuring instruments for the inclination to relapse is the likert scale, with $1=$ strongly agree, $2=$ agree, $3=$ not sure, $4=$ disagree, and 5= strongly disagree. Negative questions are re-set to $1=$ strongly disagree, $2=$ disagree, $3=$ not sure, $4=$ agree, and $5=$ strongly agree.

\section{Research Analysis}

\section{Respondent Background}

The majority of respondents in this study are between the ages of 30-39 years of Malay ethnicity and around $63.8 \%$ are married. The selected respondents who have completed their treatment and rehabilitation period, they also work to earn income and $60.2 \%$ of respondents earn less than RM1,000 a month, possibly due to lower educational background.

\section{The Main Predictor Factor on Relapse among Former Drug Addicts}

To identify the main predictor factor influencing the inclination to relapse among former drug addicts, the stepwise approach is used. Based on the stepwise regression analysis, the regression model is shown to be significant $[F(6,235)=229.72, p<0.05)]$. The results show problem-focused coping $(\beta=-$ $.210, t=-6.158, p<0.05)$, emotion-focused coping $(\beta=-.252, t=-8.030, p<0.05)$, avoidance coping ( $\beta=-$ $.078, t=-2.853, p<0.05)$, self-efficacy $(\beta=-.180, t=-5.308, p<0.05)$, family support $(\beta=-.306, t=-8.551$, $p<0.05)$, and friends support $(\beta=-.209, t=-6.029, p<0.05)$ are significant contributors to predictors for the inclination to relapse. Based on the stepwise multiple regression analysis, the problem-focused coping, emotion-focused coping, avoidance coping, self-efficacy, family support, and friend support factors are predictors to the inclination to relapse, c contributing around $85.4 \%$. This shows that six of the seven independent variables (problem-focused coping, emotion-focused coping, avoidance coping, self-efficacy, family support, and friend support) can be explained with the dependant variable (inclination to relapse). In summary, the study found that $14.6 \%$ of unpredictable changes in the criterion variable (inclination to relapse) might be caused by other variables (other factors) not considered in this study. Overall, according to Guildford's (1973) Rule of Thumb, the correlation or link between the criterion variable (inclination to relapse) and a combination of the other six identified predictor variables is recorded as .924 . The equation shows the contributions of the six predictor variables, the problem-focused coping, emotion-focused coping, avoidance coping, self-efficacy, family support, and friend support on the inclination to relapse. Based on the results, the six identified predictor variables are significant and the main contributors to the inclination to relapse. The following table illustrates the regression test analysis for the inclination to relapse. 


\begin{tabular}{|c|c|c|c|c|c|c|c|}
\hline \multirow[b]{2}{*}{ MoModel } & \multicolumn{2}{|c|}{$\begin{array}{l}\text { Unstandardized } \\
\text { Coefficients }\end{array}$} & \multirow{2}{*}{$\begin{array}{c}\text { Standardized } \\
\text { Coefficients } \\
\text { Beta }(\beta) \\
\end{array}$} & \multirow[b]{2}{*}{$\mathbf{t}$} & \multirow[b]{2}{*}{ Sig. } & \multicolumn{2}{|c|}{$\begin{array}{r}\text { Collinearity } \\
\text { Statistics }\end{array}$} \\
\hline & B & $\begin{array}{l}\text { Std. } \\
\text { Error }\end{array}$ & & & & Tolernce & VIF \\
\hline (Constant) & 2.865 & .034 & & 4.425 & .000 & & \\
\hline Focused Coping & -.086 & .014 & -.210 & 6.158 & .000 & .533 & 1.874 \\
\hline Emotion Focused Coping & -.105 & .013 & -.252 & 8.030 & .000 & .629 & 1.590 \\
\hline Avoidance Coping & -.036 & .013 & -.078 & 2.853 & .005 & .820 & 1.219 \\
\hline Self Eficacy & -.063 & 012 & -.180 & 5.308 & .000 & .541 & 1.848 \\
\hline Family Support & -.119 & .014 & -.306 & 8.551 & .000 & .485 & 2.062 \\
\hline Friends Support & -.087 & .018 & -.209 & .029 & .000 & .516 & 1.937 \\
\hline Note: $R^{2}=$ Adjusted $R^{2}=\mathrm{F}$ & 6,235 & 29.72 & & & & & \\
\hline
\end{tabular}

Table 1 : Analysis of Regression for Relapse

Direct Effect, Indirect Effect, and Total Effect

Table 2 shows the direct, indirect, and total effects for the full model towards the inclination to relapse among former drug addicts.

Table 2: Direct Effect, Indirect Effect and Total Effect on Full Model of Relapse

\begin{tabular}{|c|c|c|c|}
\hline \multirow[t]{2}{*}{ Parameter } & \multirow[t]{2}{*}{ Estimate } & \multicolumn{2}{|c|}{ 95\% Bootstrap BC Cl } \\
\hline & & Lower & Upper \\
\hline \multicolumn{4}{|l|}{ CS1 $\rightarrow$ RELAPSE } \\
\hline Total Effect standard & .419 & .159 & .301 \\
\hline Indirect Effect & .221 & & \\
\hline Direct Effect & .198 & & \\
\hline \multicolumn{4}{|l|}{ CS2 $\rightarrow$ RELAPSE } \\
\hline Total Effect standard & .473 & .148 & .307 \\
\hline Indirect Effect & .254 & & \\
\hline Direct Effect & .219 & & \\
\hline \multicolumn{4}{|l|}{ CS3 $\rightarrow$ RELAPSE } \\
\hline Total Effect standard & .479 & .112 & .160 \\
\hline Indirect Effect & .264 & & \\
\hline Direct Effect & .215 & & \\
\hline
\end{tabular}




\begin{tabular}{|c|c|c|c|}
\hline Total Effect standard & .553 & .152 & .301 \\
\hline Indirect Effect & .338 & & \\
\hline Direct Effect & .215 & & \\
\hline FS $\rightarrow$ RELAPSE & .452 & .118 & .314 \\
\hline Total Effect standard & .241 & & \\
\hline Indirect Effect & .211 & & \\
\hline \multicolumn{4}{|l|}{ Direct Effect } \\
\hline $\mathrm{FS} \rightarrow \mathrm{RELAPSE}$ & .179 & .159 & .317 \\
\hline Total Effect standard & .054 & & \\
\hline Indirect Effect & .125 & & \\
\hline Direct Effect & & & \\
\hline
\end{tabular}

Table 2 reports the standard total effect, indirect effect, and direct effect for pairs of variables in the full model passed on $95 \% \mathrm{Cl}$ (Confidence Interval). The analysis explains that all standard total effect, indirect effect, and direct effect are significant, except for peer support on the inclination to relapse. The results show the standard total effect for the family support variable is around .553. This situation explains that when family support increases by one (1) standard deviation, the inclination to relapse increases by .553 standard deviation. The standard total effect of .553 is due to both indirect effects (.338) and direct effects (.215). The indirect effect occurs because of the self-efficacy factor which functions as mediator. In fact, it is observed that the direct effect of family support on the inclination to relapse is a value of .215 , lower than the indirect effect with the value of .338 . This means family support provides a stronger indirect effect, compared to direct effect, on the inclination to relapse. The standard total effect, indirect effect, and direct effect for family support on the inclination to relapse is significant at $95 \% \mathrm{Cl}$. The avoidance coping is the second predictor for the inclination to relapse. The standard total effect for avoidance coping on the inclination to relapse is .479. The direct effect of avoidance coping on the inclination to relapse is .264. This means, when the avoidance coping increase by one (1) standard deviation, the inclination to relapse increases by .264 standard deviation. The total effect is significant at $95 \% \mathrm{Cl}$. The indirect effect occurs because of self-efficacy which functions as mediator.

Furthermore, the standard total effect of emotion-focused coping on the inclination to relapse is .473. This means when the emotion-focused coping increases by one (1) standard deviation, the inclination to relapse increases by .473 standard deviation. The standard total effect is due to the indirect effect value of .219 and the direct value of .254. The direct effect for peer support on the inclination to relapse is .452. This means, then peer support increases by one (1) standard deviation, the inclination to relapse increases by .452 standard deviation. Both direct and indirect effects occur when self-efficacy is used as the mediator variable. Next, for problem-focused coping, the standard total effect is .419. This explains when problem-focused coping increases by one (1) standard deviation, the inclination to relapse increases by .419 standard deviation. The standard total effect 
of .419 is caused by the indirect effect (.221) and direct effect (.198). The indirect effect is caused by self-efficacy that functions as mediator. Finally, for the societal support variable, the standard total deviation is .179. This explains when societal support increases by one (1) standard deviation, the inclination to relapse increases by .179 standard deviation. As observed, the direct effect of societal support on the inclination to relapse is valued .125, while the value of indirect effect is .054 . This means societal support has a stronger indirect effect, compared to direct effect, on the inclination to relapse. The standard total effect, indirect effect and direct effect for family support on the inclination to relapse is significant at $95 \% \mathrm{Cl}$. The results in Table 2 inform us that self-efficacy is significantly a mediator to link problem-focused coping, emotion-focused coping, avoidance coping, family support, peer support, and societal support, with the occurrence of a significant indirect effect based on $95 \%$ $\mathrm{Cl}$. This is proven with the occurrence of significant indirect effect on the inclination to relapse when self-efficacy is used as the mediator factor.

\section{Discussion}

This finding is in line with the findings of Cornelius, et. al, (2003), with coping being a predictor to the inclination to relapse. This means the findings from this study, whereby - coping serves as the main predictor factor to the inclination to relapse, is similar to the earlier findings. The stress faced not only caused the increase in the inclination to relapse, but also contributed to other psychological problems such as suicide, depression, and health issues (Ross, Lin \& Cunningham, 1998). This situation proves drug addicts require coping strategies to prevent the increase in the risk of relapse. Breese (2005) in his study also recognises that a lack of skills in managing stress can negatively affect an addict when faced with stress. Therefore, they require detailed planning to ensure their preparedness against pressure and in their lives. For the self-efficacy factor, the results show selfefficacy could serve as a predictor to the inclination to relapse. This argument is supported by Chong and Herman (2003) who conducted studies on American Indian women. Their findings show female American Indian addicts can only prevent relapsing for only 30 days. This study also measures mental health and self-respect, and found both mental health and self-respect to decline after the end of treatment. This situation shows former addicts can only be treated physically, while self-resilience is still in the recovering stage. For drug addicts, self-efficacy can influence the start of addiction as their expectation of satisfaction also develops their belief in their ability to relapse. In contrast, if they associate drugs with negative effects, they will put in the effort to maintain themselves from relapsing.

Furthermore, most previous studies show social support can determine the inclination to relapse among drug addicts (Goodwin, 2000; Fraser, 2002). The regression findings are also in line with a number of previous studies such as (Van Der Westhuizen, 2007) who found family support allows for positive transformation among former addicts during their rehabilitation period and build up internal trust. If the family is unable to provide support, addicts turn to other support systems that could fulfil their needs. Families play the most effective role as the main support group in the life of any individual. Addicts with supportive families will refrain from relapse, compared to addicts without such support. According to Hser, Longshore and Anglin (2007) family support is very important to prevent children from continued involvement in drug problems. Unloving, unsupportive, uncommunicating parents lead to relapse among children after the end of treatment and 
rehabilitation. According to Gouws, et. al., (2000) lack of communication, parents' inability to manage family affairs, lack of affection, parental lack of participation in children's activities, divorce, and death are among the contributing factors to the increasing risk in relapse. Aside from family support, peer support is also one predictor factor to the inclination to relapse among former addicts. This is shown in previous studies (Brandt and Delport, 2005), which found peers to affect the inclination to relapse among former addicts. Most former addicts are easily influenced by their peers, and participate in deviant activities with their chosen company. A study by Georgie, et. al., (2016) found the peer factor to show a high predictor for individual involvement in drug problems. They possibly relapse drugs because of the feeling of failure and self-guilt. This shows peers play an important role in increasing the inclination to relapse after the former addicts have undergone treatment. Therefore, the regression finding here is in line with previous studies, which found personal factors such as coping and self-efficacy, as well as social support factors such as family and peers, as significant predictors to the inclination to relapse among former drug addicts. The research findings also show both personal and interpersonal variables have strong influences on former addict's response to relapse, excepting the societal support factor.

Based on the discussion above, it is concluded the main factor for the inclination to relapse is due to the self-efficacy of former addicts, who are unable to exercise self-control against drug-use. The lack of skill and ability when faced with high-risk situations increase the inclination to relapse. Internal strength and skills in overcoming stress can encourage former addicts to avoid relapsing. Furthermore, the hope to overcome the desire for drugs has a significant effect on the efforts towards behavioural transformation, and this hope can only be improved with the presence of strong social support systems. This means positive social support systems increase the self-efficacy of former addicts to face the challenges in their lives, thus preventing their relapse. At the end of treatment and rehabilitation, former addicts need encouraging support from family, peers, and members of society, but social support is not enough to prevent them from re-using drugs. Negative societal perception leads to difficulty in communication, low self-esteem, and feeling ostracised. The result of these negative emotions is stress for the addicts, driving them to relapse, feeling unable to face challenges and built a new life.

\section{Conclusion}

Although the government has carried out various efforts to ensure the reduction of drug abuse cases in Malaysia, the issue of repeat users is still ongoing. Relapse is difficult to curb, especially with the increase in the number of relapsed addicts every year. Rehabilitating former drug addicts is not an easy task, due to the cyclical nature of relapsed addicts. The issues related to the inclination to relapse is key, and every effort must be made to help the government put a stop to this problem. Therefore, the issue of relapse must be addressed by all parties, not only family and peers, but also the government, taking into account factors contributing to their relapse.

\section{References}

Bowen, S., Chawla, N., \& Marlatt, G. A. (2010). Mindfulness-based relapse prevention for addictive behaviors: A clinician's guide. New York, NY: Guilford. 
INTERNATIONAL JOURNAL OF ACADEMIC RESEARCH IN BUSINESS AND SOCIAL SCIENCES

Vol. 10, No. 16, Youth and Community Wellbeing: Issues, Challenges and Opportunities for Empowerment V2. 2020, E-ISSN: 2222-6990 @) 2020 HRMARS

Bowen S., Witkiewitz K., Clifasefi S. L., Grow J., Chawla, N., \& Hsu S. H. (2014) Relative efficacy of mindfulness-based relapse prevention, standard relapse prevention, and treatment as usual for substance use disorders: a randomized clinical trial. JAMA Psychiatry,71(5),547-56.

Carver, C. S., Scheier, M. F., \& Weintraub, J. K. (1989). Assessing Coping Strategies: A Theoretically Based Approach. Journal of Personality and Social Psychology.56, (2), 267-283.

Chong, J., \& Herman, S. M. (2003). Substance abuse treatment outcomes among American Indians in the Telephone Aftercare Project. Journal of Psychoactive Drugs Special Issue: Morning Star Rising: Healing in Native American Communities, 35, 71-77.

Cornelius, J. R., Maisto, S. A., \& Pollock, N. K. (2003). Rapid relapse generally follows treatment for substance use disorders among adolescents. Addictive Behaviors, 28(2), 381-386.

Daley, D. C., \& Marlatt, G. A. (2006). Overcoming your alcohol and drug problem: Effective recovery strategies. Therapist Guide, 2nd ed. NY: Oxford University Press.

Daley, D. C. (2011). Relapse prevention workbook: For recovering alcohol and drug dependent persons. Revised edition. PA: Daley Publications.

Fraser, M. W. (2002). Risk and resilience in childhood. An ecological perspective. Washington: NASW. Goodwin, D. W. (2000). Alcoholism: the facts (3rd ed.). Oxford: Oxford University Press.

Gossop, M., Green, L., \& Phillips, G. (1989). Laps, relapse and survival among opiateaddicts after treatment. A prospective follow up study. British Journal Psychiatry,5,348-353.

Gouws, E., Kruger, N., \& Burger, S. (2000). The adolescent (2th ed.). Sandown: Heineman publishers.

Greenfield, S., Hufford, M., Vagge, L., Muenz, L., Costello, M., \& Weiss, R. (2000). The relationship of self-efficacy expectancies to relapse among alcohol dependent men and women: $A$ prospective study. Journal of Studies on Alcohol, 61, 345-351.

Georgie, J. M., Sean, H., Deborah, M. C., Matthew, H., \& Rona, C. (2016). Peer-led interventions to prevent tobacco, alcohol and/or drug use among young people aged 11-21 years: A systematic review and meta-analysis. Addiction, 111: 391-407.

Hser, Y., Longshore, D., \& Anglin, M. (2007). The Life Course Perspective on Drug Use: A Conceptual Framework for Understanding Drug Use Trajectories. Evaluation Review, 31(6), 515-547.

Maddux, J. E., \& Gosselin, J. T. (2003). Self-efficacy. In M. R. Leary, \& J. P. Tangney (Eds.), Handbook of self and identity (pp. 218e238). New York: The Guilford Press.

Marlatt, G. A., \& Gordon, J. R. (1985). Relapse prevention: Maintenance strategies in the treatment of addictive behaviors. New York: Guilford Press.

McWhirter, E. H., Rasheed, S., \& Crothers, M. (2000). The effects of high school career education on social-cognitive variables. Journal of Counseling Psychology, 47, 330-341.

Ross, H. E., Lin, E., \& Cunningham, J. (1999). Mental health service use: A comparison of treated and untreated individuals with substance use disorders in Ontario. Canadian Journal of Psychiatry, 44, 570-577.

Russell, D., \& Cutrona, C. E. (1987). The social provision scale: A multidimensional measure of perceived social support. In W.H. Jones \& D. Perlman (Eds.), Advances in personal relationships. Greenwich, Conn.: JAI Press.

Sharma, A. K., Upadhyaya, K. S., Bansal, P., Nijhawan, M., \& Sharma, D. M. (2012). A study of factors affecting relapse in substance abuse. Indian Sciences, 2(1), 31-35.

Sherer, M., \& Maddux, J. E. (1982). The Self-Efficacy Scale Contraction and Validation. Psychology Reports, 51, 663-671. 
Substance Abuse and Mental Health Services Administration (SAMHSA). (2014). National Recovery Month helps reduce stigma. Substance Abuse and Mental Health Services Administration. Retrieved September 17, 2020 from http://www.hazelden.org/web/public/ade20909.page.

Substance Abuse and Mental Health Services Administration, Office of Applied Studies. (2014). The NSDUH Report: Participation in self-help groups for alcohol and illicit drug use: 2012 and 2013. Retrieved September 20, 2020, from http://www.oas.samhsa.gov/2k8/selfHelp/selfHelp.pdf

Tate, S. R., Brown, S. A., Glasner, S. V., Unrod, M., \& McQuaid, J. R. (2006). Chronic life stress, acute stress events, and substance availability in relapse. Addiction Research and Theory,14, 303322.

Van Der Westhuizen, M. A. (2007), Relapsing after treatment: Exploring the experiences of chemically addicted adolescents, unpublished MA dissertation, Department of Social work, University of South Africa.

Westreich, L., Heitner, C., Cooper, M., \& Galanter, M. (1997). Perceived social support and treatment retention on an inpatient addiction treatment unit. The American Journal on Addictions, 6,144-149.

White, W. L., Campbell, M. D., Spencer, R. D., Hoffman, H. A., Crissman, B., \& DuPont, R. L. (2014). Patterns of abstinence or continued drug use among methadone maintenance patients and their relation to treatment retention. Journal of Psychoactive Drugs, 46, 114-122.

$\mathrm{Xu}, \mathrm{T}$. (2014). Intensive Use of Urban Land in New Urbanization for China: Issue and Solution. International Journal of Academic Research in Public Policy and Governace, 1(1), 143-150. 